\title{
Nutritional Screening in a University Hospital: Comparison between Oncologic and Non-Oncologic Patients
}

\author{
Selma F. C. Cunha ${ }^{1 *}$, Lidiane S. Tanaka², Roberta G. Salomão², Danielle M. Macedo², \\ Thatiane D. Santos ${ }^{2}$, Fernanda M. Peria ${ }^{3}$ \\ ${ }^{1}$ Division of Clinical Nutrition, Department of Internal Medicine, School of Medicine of Ribeirao Preto, \\ University of Sao Paulo, Ribeirao Preto, Brazil \\ ${ }^{2}$ Parenteral and Enteral Nutrition Team of Clinical Hospital, School of Medicine of Ribeirao Preto, University of \\ Sao Paulo, Ribeirao Preto, Brazil \\ ${ }^{3}$ Division of Oncology, Department of Internal Medicine, School of Medicine of Ribeirao Preto, University of \\ Sao Paulo, Ribeirao Preto, Brazil \\ Email: ${ }^{*}$ sfreire@fmrp.usp.br
}

Received 29 November 2014; accepted 9 January 2015; published 13 January 2015

Copyright (C) 2015 by authors and Scientific Research Publishing Inc.

This work is licensed under the Creative Commons Attribution International License (CC BY). http://creativecommons.org/licenses/by/4.0/

(c) $\underset{\mathrm{EY}}{\mathrm{B}}$ Open Access

\begin{abstract}
Background \& Aims: We compared the screening nutritional data of patients with malignant and non-malignant disease, and classified their nutritional risk according to the primary tumor's site. Methods: Subjective Global Assessment was applied to 3008 patients within $48 \mathrm{~h}$ of admission to a public university. Subjects were divided into Oncologic Group $(n=576)$ or Non-Oncologic Group (n $=2432$ ) according to the presence of neoplasms or other diseases respectively. These data were compared by the t-student test and classic chi-square test, with statistical significance set at $\mathbf{p}<0.05$. Results: The Oncologic Group presented a higher prevalence of weight loss $(60.3 \%$ vs. $49.3 \%)$, quantitative $(40.7 \%$ vs. $28.5 \%)$ and qualitative $(16.4 \%$ vs. $7.6 \%)$ alterations in the food intake pattern, gastrointestinal symptoms and muscle waste $(23.2 \%$ vs. $13.2 \%)$ as compared to the Non-Oncologic Group. Also, there was a higher prevalence of nutritional disturbances in the Oncologic Group, with $49.5 \%$ of the subjects moderately (or suspected to be malnourished) and $12.7 \%$ severely malnourished. Severe malnourishment was mainly observed in patients with head and neck (25\%), upper digestive tract (21.9\%) and soft tissue and bones (17.9\%) tumors. Conclusion: When compared to other hospitalized patients, patients with neoplastic disease were in higher nutritional risk.
\end{abstract}

\section{Keywords}

Nutritional Screening, Malnutrition, Subjective Global Assessment, Hospital Setting, Neoplasia

\footnotetext{
${ }^{*}$ Corresponding author.
}

How to cite this paper: Cunha, S.F.C., Tanaka, L.S., Salomão, R.G., Macedo, D.M., Santos, T.D. and Peria, F.M. (2015) Nutritional Screening in a University Hospital: Comparison between Oncologic and Non-Oncologic Patients. Food and Nutrition Sciences, 6, 75-82. http://dx.doi.org/10.4236/fns.2015.61009 


\section{Introduction}

Despite being observed more frequently in terminal cancer stages, unintentional weight loss may occur even before diagnosing the cancer itself [1]. Weight loss is related to the site of the primary tumor and cancer stage [2] [3] and even small amounts of weight loss can make the prognosis worse [1]. Physiological function is impaired in patients whose weight loss is greater than $15 \%$ of their usual weight, and death usually happens when weight loss is about 30\% [1]. The release of cytokines TNF- $\alpha$, interleukin (IL)-1 and IL-6, ciliary neurotrophic factor, interferon- $\gamma($ IFN $-\gamma)$ and catabolic products of tumor cells are some of the factors associated to the loss of fat and lean masses [4] [5]. Mechanical factors related to gastrointestinal tumors, side effects of the treatment and alterations in energetic metabolism also contribute to deteriorate the nutritional status [6].

Generally, the chances of complications are higher in oncology patients who show a more serious nutritional injury [7]. It is assumed that about $20 \%$ of cancer deaths are related to malnutrition rather than to the disease itself [1]. The worsening of the nutritional status is associated with a bad prognosis, a higher occurrence of side effects of the treatment and a worse quality of life [1] [2] [4] [8].

In the absence of formal screening procedures, more than half the patients at risk of malnutrition in various settings do not appear to be recognized and/or are not referred for treatment [9]. An early and well-planned nutritional approach could improve the clinical outcome of oncologic patients [10]. Many times, the nutritional screening of these patients is not performed, or when it is, it is too late to change prognosis [7]. On the other hand, indiscriminate nutrition support prescription to cancer patients might result in complications such as hyperglycemia, alteration of respiratory rate and hyperphosphatemia [10]. In this context, effective screening makes early identification of patients in nutrition risk possible, which must be forwarded for more thorough assessment [11] and redirected for optimal nutritional intervention [3] [10].

This study aimed to compare nutritional screening data of recently admitted adult oncologic and non-oncologic patients. Besides, this study aimed to compare the nutritional status of the oncologic patients according to the anatomic site of the primary tumor.

\section{Casuistic and Methods}

This study was conducted in a university hospital in 2009 and 2010, after approval by the Institutional Ethics Committee (Protocol \#13530). The initial casuistic included data of nutritional screening of 3450 recently admitted adult patients ( $<48$ hours after admittance). The data were collected by trained dieticians and individual information was revised by three independent observers (two physicians and one dietician). The final casuistic comprised 3008 patients from different wards after excluding misleading cases or those with incomplete information $(\mathrm{n}=442)$.

The Subjective Global Assessment (SGA) for nutritional screening [12] was performed. Habitual and current body weight was measured, and weight change in the six months prior to assessment calculated. Weight loss was classified as small $(<5 \%)$, moderate $(5 \%-10 \%)$ or high $(>10 \%)$. Unintentional reduction in food intake, inadequate eating habits marked by exclusive intake of poor nutritional foods, gastrointestinal symptoms with duration of at least two weeks and alterations in functional capacity were registered. The clinical diagnoses were obtained from patients' health records and the degree of metabolic stress was determined. A simplified physical exam was performed to identify clinical manifestations of malnutrition (loss of subcutaneous fat, muscle wasting, edema and ascites). According to the criteria described above, the patients were classified as well nourished, moderately (or suspected of being) malnourished or severely malnourished.

The patients were allocated to Oncologic Group $(n=576)$ or Non-Oncologic Group ( $n=2432)$, according to the nature of the primary diseases, determined by the clinical or surgical diagnoses registered on the electronic health records. Most patients were women in both groups (Table 1). The percentage of male patients (47.6 vs. $42.6 \%, \mathrm{p}=0.03)$ and age $(59.2 \pm 15.2$ vs. $51.4 \pm 17.1$ years, $\mathrm{p}<0.001)$ were greater in the Oncologic Group as compared to the other group. The Oncologic Group individuals were subdivided into 12 categories according to the primary tumor location: 1) upper digestive tract (esophagus, stomach, duodenum, small intestine, pancreas, liver, gallbladder and bile ducts); 2) hematologic; 3) gynecologic (ovary, uterus, vulva and vagina); 4) lower digestive tract (colon, rectum and anal canal); 5) head and neck; 6) lung and pleural; 7) soft tissue and bone; 8) breast; 9) central nervous system; 10) urologic; 10) skin and 12) endocrine.

Data were analyzed statistically using the Statistica software (version 8.0, StatSoft Inc., Tulsa, Oklahoma). The t-student test was used and results are shown as mean $\pm \mathrm{SD}$. Chi-square test was used to compare unpaired 
proportions of categorical variables. Two-tailed p values $<0.05$ were considered statistically significant.

\section{Results}

Weight loss less than $10 \%$ of usual body weight was similar between the groups (Table 2). However, the Table 1. Socio-demographic characteristics of the oncologic and non-oncologic patients.

\begin{tabular}{ccccc} 
& & Oncologic Group $(\mathrm{n}=576)$ & Non-Oncologic Group $(\mathrm{n}=2432)$ & p value \\
\hline \multirow{2}{*}{ Gender (\%) } & Male & 47.6 & 42.6 & 0.03 \\
& Female & 52.4 & 57.4 & $<0.001$ \\
\hline
\end{tabular}

Table 2. Subjective Global Assessment parameters in oncologic and non-oncologic patients recently admitted to a university hospital.

\begin{tabular}{|c|c|c|c|}
\hline & Oncologic Group $(n=576)$ & Non-Oncologic Group $(\mathrm{n}=2432)$ & p value \\
\hline \multicolumn{4}{|c|}{ Changes in body weight } \\
\hline Weight 6 months prior to study (kg) & $68.7 \pm 15.5$ & $72.3 \pm 18.1$ & $<0.00001$ \\
\hline Current weight (kg) & $65.7 \pm 15.2$ & $70.8 \pm 18.1$ & $<0.00000$ \\
\hline Patients who lost weight (\%) & 60.8 & 49.2 & $<0.00000$ \\
\hline \multicolumn{4}{|l|}{ From which: } \\
\hline$<5 \%$ of habitual weight (\%) & 32.4 & 36.1 & 0.22 \\
\hline $5 \%-10 \%$ of habitual weight (\%) & 26.5 & 30.4 & 0.17 \\
\hline$>10 \%$ of habitual weight (\%) & 41.1 & 33.5 & 0.01 \\
\hline \multicolumn{4}{|c|}{ Changes in dietary intake } \\
\hline Reduction of food intake (\%) & 40.4 & 28.6 & $<0.00000$ \\
\hline Liquid and semi-liquid food (\%) & 16.3 & 7.6 & $<0.00000$ \\
\hline \multicolumn{4}{|c|}{ Gastrointestinal symptoms } \\
\hline Anorexia (\%) & 20.5 & 12.7 & $<0.00000$ \\
\hline Nausea (\%) & 21.2 & 14.2 & 0.00004 \\
\hline Vomiting (\%) & 12.0 & 5.9 & 0.00000 \\
\hline Diarrhea (\%) & 8.3 & 5.0 & 0.002 \\
\hline \multicolumn{4}{|c|}{ Functional capacity } \\
\hline No dysfunction (\%) & 64.6 & 68.1 & 0.12 \\
\hline Working suboptimally (\%) & 26.0 & 24.6 & 0.47 \\
\hline Ambulatory (\%) & 5.9 & 4.4 & 0.11 \\
\hline Bedridden (\%) & 3.5 & 2.9 & 0.7 \\
\hline \multicolumn{4}{|c|}{ Disease and its relation to nutritional requirements } \\
\hline Inflammatory stress (\%) & 100 & 12.9 & 0.00000 \\
\hline \multicolumn{4}{|c|}{ Physical } \\
\hline Loss of subcutaneous fat (\%) & 19.0 & 11.4 & 0.09 \\
\hline Muscle wasting (\%) & 23.0 & 13.3 & 0.00000 \\
\hline Edema (\%) & 24.2 & 21.6 & 0.19 \\
\hline
\end{tabular}


Oncologic Group presented a higher percentage of patients with a history of weight loss greater than $10 \%(41.1 \%$ vs. $33.5 \%, \mathrm{p}=0.01)$, as well as reduction in food intake $(40.4 \%$ vs. $28.6 \%, \mathrm{p}<0.00000)$ and substitution of solid foods with liquid and semi-liquid food $(16.3 \%$ vs. $7.6 \%, \mathrm{p}<0.00000)$. Prevalence of gastrointestinal symptoms persisting for more than 2 weeks, including anorexia $(20.5 \%$ vs. $12.7 \%, p<0.00000)$, nausea $(21.2 \%$ vs. $14.2 \%, \mathrm{p}=0.00004)$, vomiting $(12.0 \%$ vs. $5.9 \%, \mathrm{p}=0.00000)$ and diarrhea $(8.3$ vs. $5.0, \mathrm{p}=0.002)$ was higher in the Oncologic Group as compared to Non-Oncologic Group. There were no differences in the functional capacity, loss of subcutaneous fat and edema between the groups. On the other hand, Oncologic Group presented a higher percentage of patients with muscle wasting $(23.0 \%$ vs. $13.3 \%, \mathrm{p}=0.00000)$.

According to the SGA rating, the Oncologic Group presented a higher prevalence of patients with some degree of malnourishment (moderately or suspected of being malnourished or severely malnourished) as compared to the Non-Oncologic Group (Figure 1). A higher prevalence of moderate (or suspected) malnourishment was observed in patients with hematologic (72.4\%), upper (63\%) and lower (61.7\%) digestive tract tumors. Furthermore, those with head and neck (25\%), upper digestive tract (21.9\%) and soft tissue and bone tumors (7.9\%) presented a higher prevalence of severe malnourishment (Table 3).

\section{Discussion}

This study demonstrated that hospitalized patients with malignant disease presented a higher prevalence of weight loss, reduced food intake, gastrointestinal symptoms and muscle wasting than non-oncologic patients. In the SGA final results, the patients with malignant disease showed a higher prevalence of moderate (or suspected) or severe malnourishment. Patients with head and neck, upper digestive tract and soft tissue and bone tumors presented a higher prevalence of severe malnourishment.

In general, changes in food intake behavior are secondary to gastrointestinal symptoms, such as mild to severe dysgeusia/dysosmia and dysphagia/odynophagia [13] which lead to physical inability to eat adequately. The number of gastrointestinal symptoms, especially anorexia, has been associated to the severity of weight loss [2] [14] and nutritional parameters [15].

In our study, anorexia was not observed in the majority of patients with no weight loss or with a weight loss less than $10 \%$ of their usual body weight. The frequency of anorexia in this study (20\%) was similar to that found by Gómez-Candela and colleagues (2003) [16] and lower than the frequency presented in other studies [7] [13] [17] and may be related to changes in food intake and sensation of early satiety related to the central nervous system [18]. Frequency of nausea (21\%) and vomiting (12\%) in oncologic patients was similar to previously described data [2] [7] [13] [16] and lower than that observed by Sarhill and colleagues (2003) [14] in a study on terminal patients. The frequency of diarrhea in oncologic patients was similar to that observed by Segura and colleagues (2005) [13] (6.7\%) and lower than the frequency reported by Sarhill and colleagues (2003) [14] (24\%). Several studies on oncologic patients have reported changes in intestinal transit in these patients. However,

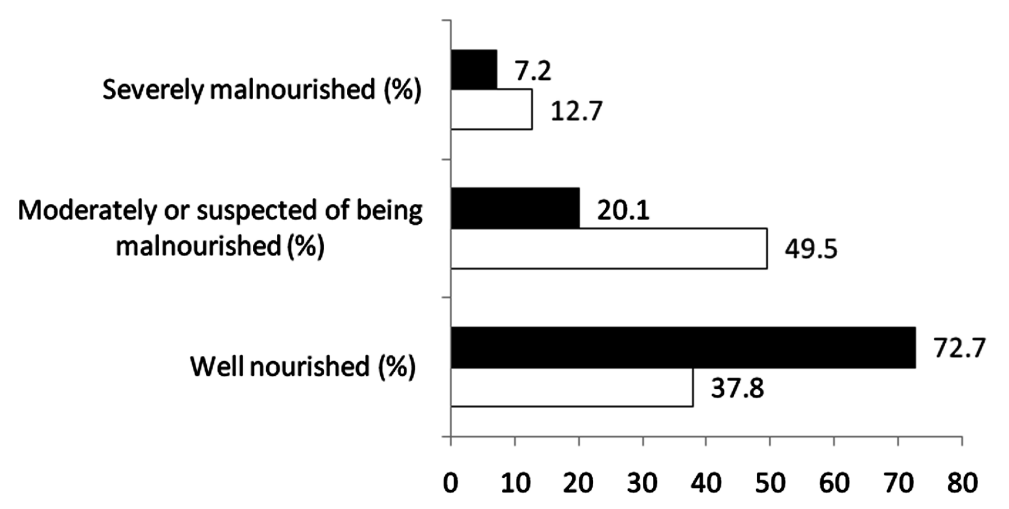

\section{- Non-oncologic Group $\quad$ 口Oncologic Group}

Figure 1. Subjective Global Assessment rating of recently admitted adult patients, allocated in Oncologic $(n=576)$ and Non-Oncologic Group $(n=2432)$. 
Table 3. Subjective Global Assessment rating in 576 patients with malignant disease, according to the primary tumor anatomic location.

\begin{tabular}{|c|c|c|c|c|}
\hline \multirow{2}{*}{ Tumor anatomic location } & \multirow[b]{2}{*}{$\mathrm{n}$} & \multicolumn{3}{|c|}{ Subjective Global Assessment rating } \\
\hline & & Well nourished (\%) & $\begin{array}{c}\text { Moderately or suspected of being } \\
\text { malnourished (\%) }\end{array}$ & Severely malnourished (\%) \\
\hline Upper digestive tract & 73 & 15.1 & 63.0 & 21.9 \\
\hline Hematologic & 29 & 17.3 & 72.4 & 10.3 \\
\hline Gynecologic & 71 & 26.8 & 57.7 & 15.5 \\
\hline Lower digestive tract & 60 & 28.3 & 61.7 & 10.0 \\
\hline Head and neck & 44 & 29.5 & 45.5 & 25.0 \\
\hline Lung and pleura & 32 & 34.4 & 56.2 & 9.4 \\
\hline Soft tissue and bone & 28 & 46.4 & 35.7 & 17.9 \\
\hline Breast & 88 & 48.9 & 42.2 & 7.9 \\
\hline Central nervous system & 10 & 50.0 & 50.0 & 0 \\
\hline Urologic & 84 & 51.2 & 39.3 & 9.5 \\
\hline Skin & 33 & 54.5 & 36.3 & 9.1 \\
\hline Endocrine & 24 & 83.3 & 16.7 & 0 \\
\hline All tumors & 576 & 37.8 & 49.5 & 12.7 \\
\hline
\end{tabular}

differently from our study, a number of them have considered both diarrhea and constipation [2], which made it difficult to compare our results.

The prevalence of changes in functional capacity in the Oncologic Group was similar to the prevalence found in previous studies [16] [17]. However, we also observed a reduction in functional capacity in the non-oncologic group, which indicates that such clinical manifestation may be associated with other diseases and conditions, including hospitalization per se. The subjects in the Oncologic Group presented a higher prevalence of muscle wasting, which can be related to a reduction in the myofibrillar proteins synthesis and/or increased proteolysis [5] [19] induced by pro-inflammatory milieu [4]. Malnourished cancer patients commonly have increased wholebody protein turnover and subsequent body nitrogen loss, which result in progressive reduction of skeletal muscle while liver mass may increase and the visceral protein reserves are preserved [1]. Diminished functional capacity of organ systems may be caused by loss of lean tissue, although its detection might be difficult due to an accumulation of water which might mask the alterations [1].

In the Non-Oncologic Group, $7 \%$ of patients were severely malnourished and $20 \%$ was moderately or suspected of being malnourished. This prevalence was lower than that observed in 2550 hospitalized non-oncologic patients in four teaching hospitals in China, with $18 \%$ of malnourished patients and $41.5 \%$ at nutritional risk [20]. The degree of malnutrition or nutritional risk (62\%) in our Oncologic Group was similar to that found in a multicentric, cross-sectional study performed in public hospitals in Brazil (66\%), in which cancer patients had an almost three-fold higher rate of malnutrition than non-oncologic patients [21]. Sixty-four percent of patients admitted to a public, oncology hospital in Australia were at risk of malnutrition [22]. Nearly 50\% of hospitalized oncologic patients are malnourished [13] [17], although the prevalence of risk of malnutrition may exceed 70\% among these patients [7] [23].

The prevalence of nutritional disturbances in patients with neoplasia in the upper and lower digestive tract and in head and neck cancer were higher than those reported in previous studies (50\% - 70\%) [5] [17] [24] [25]. The prevalence of nutritional risk in oncology patients is quite variable among studies, partly because of differences in the studied populations [26], including age [9], type and treatment of tumor [27], setting, site and stage of neoplastic disease [17]. Oncology inpatients are generally more nutritionally compromised than those who are treated in an ambulatory setting [2]. According to the PG-SGA, the prevalence of malnutrition was $17 \%$ in an outpatient oncology day treatment unit in a tertiary health service in Australia [28]. In our study, all patients 
were hospitalized for diagnosis, neoplasm stating, surgery or palliative care, which may explain the greater prevalence of malnutrition in our population. Furthermore, even though there is an agreement regarding the identification of severe malnourishment among different professionals, there is no consensus on the definition or identification of mild and moderate malnutrition [16]. The proportion of patients nutritionally at risk depends on the screening tools used [11]. For instance, the prevalence of malnutrition in head and neck cancer patients varied according to the evaluation tool, with 35\% by using the NRS-2002, 30\% using MUST and 48\% using the MST [29]. The absence of a universally accepted definition of malnutrition negatively affects the existence of a screening instrument considered as gold standard [9].

The main strength of this study was the size of the casuistic. The protocol was seen as adequately specific and sensitive when used in prospective clinical trials on cancer patients [10]. In the present study, the prevalence of malnutrition in patients with several types of cancer was analyzed separately, which allowed to highlight the types of cancer most associated with nutritional disturbances. A weakness of this study was the lack of information about the modality of treatment and tumor stage, the latter being considered as a better prognostic index than SGA [30].

The adoption of a minimum set of standards for nutritional screening has been recommended for hospitals and healthcare organizations [31]. Nutritional screening could also establish a more efficient referral system [32], since not all patients need to be referred to specialists for further evaluation and/or treatment [9]. Policies need to take into account local resources, but at the same time ensure that adequate standards of care are maintained [9].

\section{Conclusion}

When compared to other hospitalized patients, patients with neoplastic disease presented higher nutritional risk and varied degrees of malnutrition, expressed as weight loss, anorexia, gastrointestinal symptoms and physical signs. Patients with neoplasm in the upper and lower digestive tract, head and neck, and hematologic or gynecologic tumors presented the highest prevalence of nutritional risk and malnutrition. Our findings emphasize the necessity of using nutritional screening protocols in patients with malignant neoplastic diseases for developing early strategies for nutritional intervention.

\section{Acknowledgements}

We thank the interns of the Parenteral and Enteral Nutrition Team of HCFMRP for their participation in data collection (in alphabetical order): Ana Luiza Knudsen Cardoso, Isabela Theófilo Gava, Jana Paula da Silva, Juliana Eiko Yueno, Larissa Godoy, Maísa Bendlin Rockenbach, Mirela Cristina De Marco, Patrícia Cesarino Fram and Stella Maria Franzoni Godoy.

\section{Disclosure Statement}

None of the authors had any personal or financial conflicts of interest. All authors attest and affirm that the material within has not been and will not be submitted for publication elsewhere.

\section{References}

[1] Tisdale, M.J. (2002) Cachexia in Cancer Patients. Nature Reviews Cancer, 2, 862-871. http://dx.doi.org/10.1038/nrc927

[2] Bozzetti, F., Arends, J., Lundholm, K., Micklewright, A., Zucher, G. and Muscaritoli, M. (2009) ESPEN Guidelines on Parenteral Nutrition: Non-Surgical Onconlogy. Clinical Nutrition, 28, 445-454. http://dx.doi.org/10.1016/j.clnu.2009.04.011

[3] Huhmann, M.B. and Cunningham, R.S. (2005) Importance of Nutritional Screening in Treatment of Cancer-Related Weight Loss. Lancet Oncology, 6, 334-343. http://dx.doi.org/10.1016/S1470-2045(05)70170-4

[4] Arends, J., Bodoky, G., Bozzetti, F., Fearon, K., Muscaritoli, M., Selga, G., van Bokhorst-de van der Schueren, M.A. and von Meyenfeldt, M., DGEM (German Society for Nutritional Medicine); Zürcher, G., Fietkau, R., Aulbert, E., Frick, B., Holm, M., Kneba, M., Mestrom, H.J. and Zander, A., ESPEN (European Society for Parenteral and Enteral Nutrition) (2006) ESPEN Guidelines on Enteral Nutrition: Non-Surgical Oncology. Clinical Nutrition, 25, 245-259. http://dx.doi.org/10.1016/j.clnu.2006.01.020 
[5] De Blaauw, I., Deutz, N.E.P. and Von Meyenfeldt, M.F. (1997) Metabolic Changes in Cancer Cachexia—First of Two Parts. Clinical Nutrition, 16, 169-176. http://dx.doi.org/10.1016/S0261-5614(97)80002-7

[6] Aspen Board of Directors and the Clinical Guidelines Task Force (2002) Guidelines for the Use of Parenteral and Enteral Nutrition in Adult and Pediatric Patients. Journal of Parenteral and Enteral Nutrition, 26, 1SA-138SA.

[7] Borges, N.P., D’Alegria-Silva, B., Cohen, C., Portari Filho, P.E. and Medeiros, F.J. (2009) Comparison of the Nutritional Diagnosis, Obtained through Different Methods and Indicators, in Patients with Cancer. Nutricion Hospitalaria, 24, 51-55.

[8] Geirsdottir, O.G. and Thorsdottir, I. (2008) Nutritional Status of Cancer Patients in Chemotherapy, Dietary Intake, Nitrogen Balance and Screening. Food \& Nutrition Research, 52.

[9] Elia, M., Zellipour, L. and Stratton, R.J. (2005) To Screen or Not to Screen for Adult Malnutrition? Clinical Nutrition, 24, 867-884. http://dx.doi.org/10.1016/j.clnu.2005.03.004

[10] Huhmann, M.B. and August, D.A. (2008) Review of American Society for Parenteral and Enteral Nutrition (A.S.P.E.N.) Clinical Guidelines for Nutrition Support in Cancer Patients: Nutrition Screening and Assessment. Nutrition in Clinical Practice, 23, 182-188. http://dx.doi.org/10.1177/0884533608314530

[11] Raslan, M., Gonzalez, M.C., Torrinhas, R.S.M.M., Ravacci, G.R., Pereira, J.C.R. and Waitzberg, D.L. (2011) Complementarity of Subjective Global Assessment (SGA) and Nutritional Risk Screening 2002 (NRS 2002) for Predicting Poor Clinical Outcomes in Hospitalized Patients. Clinical Nutrition, 30, 49-53. http://dx.doi.org/10.1016/j.clnu.2010.07.002

[12] Detsky, A.S., McLaughlin, J.R., Baker, J.P., Johnston, N., Whittaker, S., Mendelson, R.A. and Jeejeebhoy, K.N. (1987) What Is Subjective Global Assessment of Nutritional Status? Journal of Parenteral and Enteral Nutrition, 11, 8-13. http://dx.doi.org/10.1177/014860718701100108

[13] Segura, A., Pardo, J., Jara, C., Zugazabeitia, L., Carulla, J., de Las Peñas, R., García-Cabrera, E., Luz Azuara, M., Casadó, J. and Gómez-Candela, C. (2005) An Epidemiological Evaluation of the Prevalence of Malnutrition in Spanish Patients with Locally Advanced or Metastatic Cancer. Clinical Nutrition, 24, 801-814. http://dx.doi.org/10.1016/j.clnu.2005.05.001

[14] Sarhill, N., Mahmoud, F., Walsh, D., Nelson, K.A., Komurcu, S., Davis, M., LeGrand, S., Abdullah, O. and Rybicki, L. (2003) Evaluation of Nutritional Status in Advanced Metastatic Cancer. Supportive Care in Cancer, 11, 652-659. http://dx.doi.org/10.1007/s00520-003-0486-0

[15] Bovio, G., Montagna, G., Bariani, C. and Baiardi, P. (2009) Upper Gastrointestinal Symptoms in Patients with Advanced Cancer: Relationship to Nutritional and Performance Status. Supportive Care in Cancer, 17, 1317-1324. http://dx.doi.org/10.1007/s00520-009-0590-x

[16] Gómez-Candela, C., Luengo, L.M., Cos, A.I., Martínez-Roque, V., Iglesias, C., Zamora, P. and González-Barón, R. (2003) Subjective Global Assessment in Neoplastic Patients [Valoración Global Subjetiva en el Paciente Neoplásico]. Nutrición Hospitalaria, 18, 353-357.

[17] Cid Conde, L., Fernández López, T., Neira Blanco, P., Arias Delgado, J., Varela Correa, J.J. and Gómez Lorenzo, F.F. (2008) Hyponutrition Prevalence among Patients with Digestive Neoplasm before Surgery [Prevalencia de Desnutrición em Pacientes com Neoplasia Digestiva Previa Cirurgia]. Nutrición Hospitalaria, 23, 46-53.

[18] von Meyenfeldt, M. (2005) Cancer-Associated Malnutrition: An Introduction. European Journal of Oncology Nursing, 9, 35-38. http://dx.doi.org/10.1016/j.ejon.2005.09.001

[19] Khal, J., Hine, A.V., Fearon, K.C., Dejong, C.H. and Tisdale, M.J. (2005) Increased Expression of Proteasome Subunits in Skeletal Muscle of Cancer Patients with Weight Loss. International Journal of Biochemistry \& Cell Biology, 37, 2196-2206. http://dx.doi.org/10.1016/j.biocel.2004.10.017

[20] Fang, S., Long, J., Tan, R., Mai, H., Lu, W., Yan, F. and Peng, J. (2013) A Multicentre Assessment of Malnutrition, Nutritional Risk, and Application of Nutritional Support among Hospitalized Patients in Guangzhou Hospitals. Asia Pacific Journal of Clinical Nutrition, 22, 54-59.

[21] Waitzberg, D.L., Caiaffa, W.T. and Correia, M.I.T.D. (2001) Hospital Malnutrition: The Brazilian National Survey (IBRANUTRI): A Study of 4000 Patients. Nutrition, 17, 573-580. http://dx.doi.org/10.1016/S0899-9007(01)00573-1

[22] Boltong, A.G., Loeliger, J.M. and Steer, B.L. (2013) Using a Public Hospital Funding Model to Strengthen a Case for Improved Nutritional Care in a Cancer Setting. Australian Health Review, 37, 286-290. http://dx.doi.org/10.1071/AH13010

[23] Shaw, C., Fleuret, C., Pickard, J.M., Mohammed, K., Black, G. and Wedlake, L. (2014) Comparison of a Novel, Simple Nutrition Screening Tool for Adult Oncology Inpatients and the Malnutrition Screening Tool (MST) against the Patient-Generated Subjective Global Assessment (PG-SGA). Supportive Care in Cancer, 23, 47-54. http://dx.doi.org/10.1007/s00520-014-2319-8

[24] Wu, B.W., Yin, T., Cao, W.X., Gu, Z.D., Wang, X.J., Yan, M. and Liu, B.Y. (2009) Clinical Application of Subjective 
Global Assessment in Chinese Patients with Gastrointestinal Cancer. World Journal of Gastroenterology, 15, 35423549. http://dx.doi.org/10.3748/wjg.15.3542

[25] Righini, C.A., Timi, N., Junet, P., Bertolo, A., Reyt, E. and Atallah, I. (2013) Assessment of Nutritional Status at the Time of Diagnosis in Patients Treated for Head and Neck Cancer. European Annals of Otorhinolaryngology, Head and Neck Diseases, 130, 8-14. http://dx.doi.org/10.1016/j.anorl.2012.10.001

[26] De Blaauw, I., Deutz, N.E.P. and Von Meyenfeldt, M.F. (1997) Metabolic Changes in Cancer Cachexia-Second of Two Parts. Clinical Nutrition, 16, 223-228. http://dx.doi.org/10.1016/S0261-5614(97)80033-7

[27] van Cutsem, E. and Arends, J. (2005) The Causes and Consequences of Cancer-Associated Malnutrition. European Journal of Oncology Nursing, 9, 51-63. http://dx.doi.org/10.1016/j.ejon.2005.09.007

[28] Abbott, J., Teleni, L., McKavanagh, D., Watson, J., McCarthy, A. and Isenring, E. (2014) A Novel, Automated Nutrition Screening System as a Predictor of Nutritional Risk in an Oncology Day Treatment Unit (ODTU). Supportive Care in Cancer, 22, 2107-2112. http://dx.doi.org/10.1007/s00520-014-2210-7

[29] Amaral, T.F., Cabral, S., Alves, P. and Kent-Smith, L. (2008) An Evaluation of Three Nutritional Screening Tools in a Portuguese Oncology Centre. Journal of Human Nutrition and Dietetics, 21, 575-583. http://dx.doi.org/10.1111/j.1365-277X.2008.00917.x

[30] Wakahara, T., Shiraki, M., Murase, K., Fukushima, H., Matsuura, K., Fukao, A., Kinoshita, S., Kaifuku, N., Arakawa, N., Tamura, T., Iwasa, J., Murakami, N., Deguchi, T. and Moriwaki, H. (2007) Nutritional Screening with Subjective Global Assessment Predicts Hospital Stay in Patients with Digestive Diseases. Nutrition, 23, 634-639. http://dx.doi.org/10.1016/j.nut.2007.06.005

[31] Kondrup, J., Allison, S.P., Elia, M., Vellas, B. and Plauth, M. (2003) ESPEN Guidelines for Nutrition Screening 2002. Clinical Nutrition, 22, 415-421. http://dx.doi.org/10.1016/S0261-5614(03)00098-0

[32] Kruizenga, H.M., Van Tulder, M.W., Seidell, J.C., Thijs, A., Ader, H.J. and van Bokhorst-de van der Schueren, M.A. (2005) Effectiveness and Cost-Effectiveness of Early Screening and Treatment of Malnourished Patients. American Journal of Clinical Nutrition, 82, 1082-1089. 
Scientific Research Publishing (SCIRP) is one of the largest Open Access journal publishers. It is currently publishing more than 200 open access, online, peer-reviewed journals covering a wide range of academic disciplines. SCIRP serves the worldwide academic communities and contributes to the progress and application of science with its publication.

Other selected journals from SCIRP are listed as below. Submit your manuscript to us via either submit@scirp.org or Online Submission Portal.
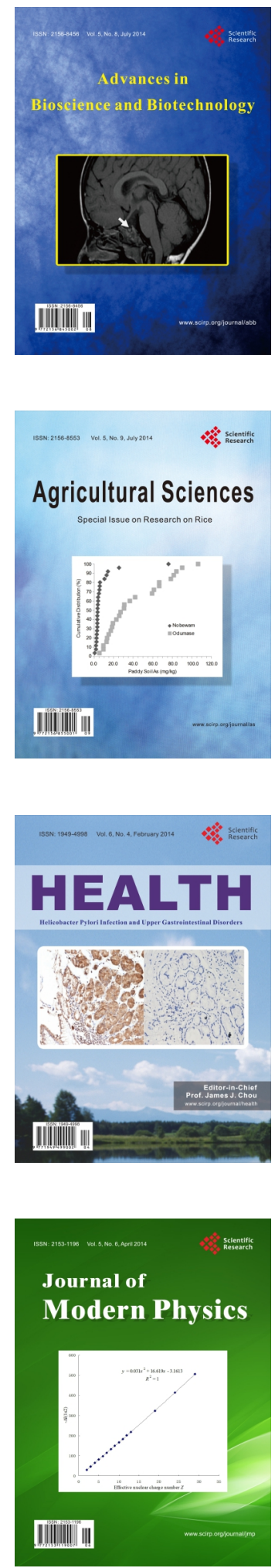
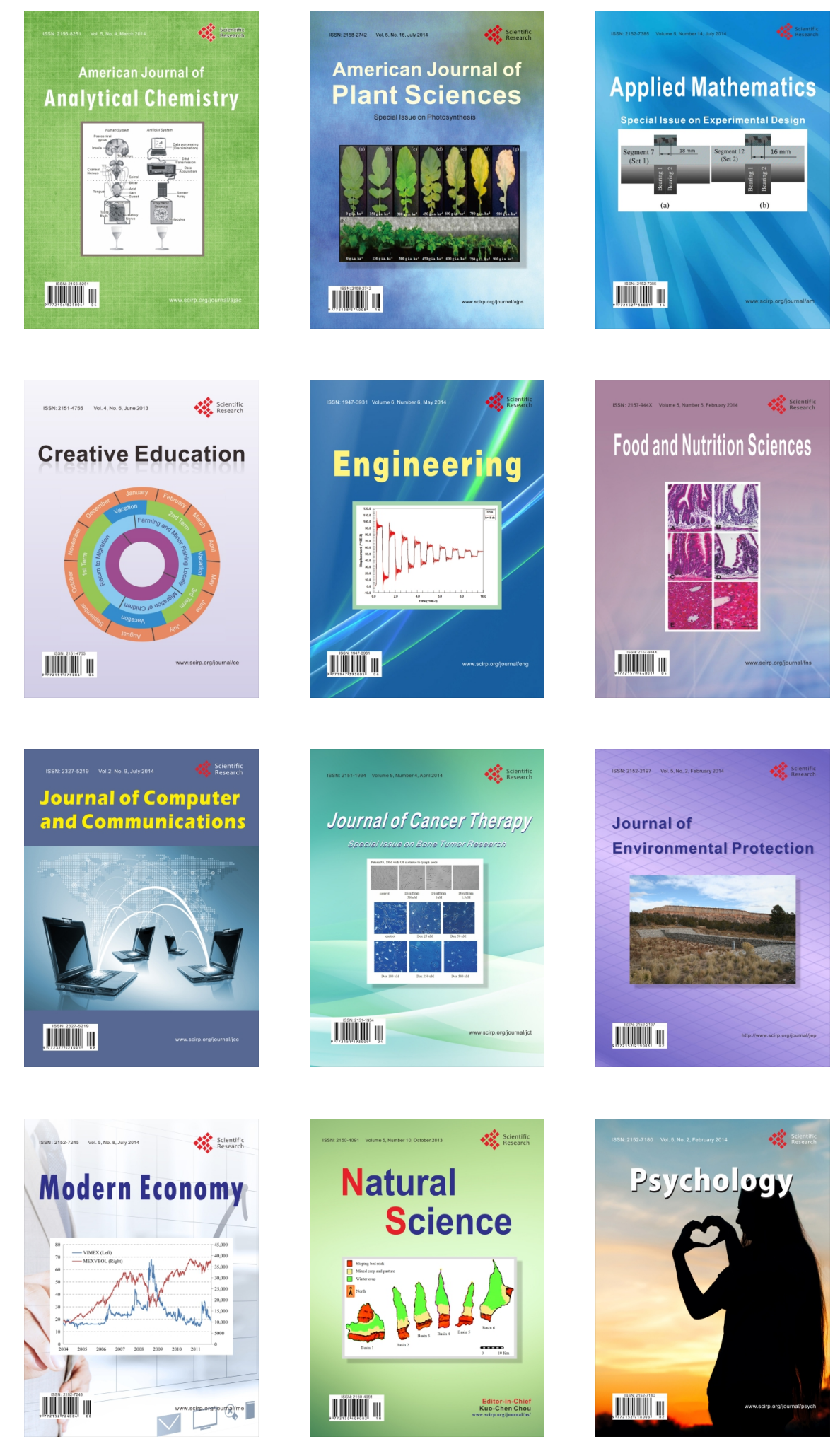